\title{
THE USE OF SOCIAL MEDIA IN RESOLVING MARITAL CONFLICT
}

\author{
Oguadinma Pamella Oluchukwu (corresponding author) \\ Faculty of Culture and social development, Department of Sociology, Southwest University, \\ Chongqing, 400715, CHINA
}

\begin{abstract}
It is no doubt that there have been consistently increasing advances in the general population of educated people, technologies, and breakthroughs in scientific and social research, yet, the issue of marital conflict in today's world is spontaneously on the rise. The central theme of this research work is to examine the influence of social media on marital conflict resolution in Anambra state of Western Africa. Married individuals were used as key attributes, and the study adopted the functionalist theory as the theoretical framework while utilizing multi-stage sampling techniques in the selection of 200 respondents for the survey. Qualitative and quantitative data collection techniques were adopted through the use of the in-depth interview guide and data collected through the use of questionnaires, respectively. Responses from the survey were analyzed using frequency distribution tables and simple percentages. Findings from the study revealed that marital conflict could be resolved and strengthened with the use of social media. The study recommends the set-up of frequent radio and television programs on marriage and relationship issues that will educate couples on how to use social media best to avoid marital conflict.
\end{abstract}

Keywords: Social media; Marital conflict; Married couple; quantitative data; Communication

\section{Introduction}

Despite the increasing advances in the general population of educated people, technologies, and breakthroughs in scientific and social research, the issue of marital conflict in today's world is spontaneously on the rise. While marriages of the previous centuries lasted long, those of the twenty-first centuries seem to be depreciating in constant regression exponential. These conflicts in marriages are mostly the case with couples in Anambra state, a rather medium community in eastern Nigeria. Cox and Paley (1997) argued that, though couples and family interconnectedness and interdependency could be beneficial, it could as well be detrimental and lead to marital conflict. The bonds built due to social activities could buffer stress responses in humans (Cohen and Wills, 1985; Hostinar, Sullivan, and Gunnar, 2014), maintaining mental and physical health (Uchino, 2006; Robles, Slatcher, Trombello, and McGuinn, 2014). This connectedness built through social activities could transfer stress from one couple to the other, causing marital instability. Timmons et al. (2017) study shows that for many married individuals, the ups and downs of daily life could create a stressful experience that may "spillover" to negatively impact marital functioning.

Observing the frequent case of decreased psychological performance, domestic violence, and high rate of divorce among the populace within the study area, it was, therefore, crucial to conduct a study on how to address the issue of marital conflict using a method and strategy that could easily be accessible to all. This study addressed the issue of marital conflict using social media platforms, and that could be accessed through 
technological devices like personal computers, mobile phones, other gadgets, etc.

\subsection{Resolving marriage conflict}

Several researchers have sought to understand and identify marital conflict and how to resolve it better. Norgren et al. (2004) concluded in his study (Marital satisfaction in long-lasting marriages: A feasible construction) that problem solving and communication strategies were instrumental in conflict resolution. Birditt et al. (2010) conducted similar research on 373 North-American couples and found that the problemsolving approach, which consists of interpersonal character (Gottman 1994), adopted by couples, helped resolve conflicts. Kurdek (1994b) had earlier classified marital conflict resolution style into four categories which are; positive, withdrawal, compliance, and conflict engagement. These resolution strategies use negotiation and compromise, long periods of silence, acceptance of any solution to avoid discussion of conflict and personal attacks, and loss of behavioral control to solve issues related to marital conflict, respectively. Kurdek (1994b) style of problem-solving in marriages seem feasible except for the fourth category, which involves personal attacks and loss of behavioral control. This fourth category would instead, in most cases, prolong the time it takes to resolve conflict and will decrease the chance of openness to a subtler discussion to reach better understanding agreements. The personal attack and loos of behavioral control is a negative approach to conflict resolution, and McNulty and Russel (2010) highlighted that unhappy couples also tend to make use of few negative problem-solving strategies at the beginning of their relationships. Couples who adopt negative problem-solving styles also show decreased marital satisfaction (Ridley et al. 2001). Positive problem-solving strategies exist and have been found to lead to marriage satisfaction in partners of a different culture (Dush \& Taylor, 2012; Leggett, Roberts-Pittman, Byczek, \& Morse, 2012; Ridley et al., 2001; Scheeren et al., 2014). This fact was made evident by Dong and Li (2007), who, in his study of 735 Chinese, married women, revealed that problems should not be avoided but discussed and solved to achieve a high-quality relationship. Also, research in Iran shows that enhancing communication and conflict resolution skills could pose a positive influence on the quality of marriage (Askari et al., 2012).

\subsection{Social media in conflict resolution}

The term social media refers to a wide range of internet-based and mobile services that allow users to participate in online exchanges, contribute user-created content or join online communities. It also refers to the use of web-based and mobile technologies to turn communication into interactive dialogue, and they can take different forms, including; internet forums, weblogs, social blogs, wikis, podcasts, photographs or pictures, videos, rating and social bookmarking.

It is widely known by many that social media sites like Facebook, Twitter, and the rest of the vast universe of social media can pose a specific threat to marriages, especially those going through difficult times. Despite those hitches, depending on how it is being used, social media can make a marriage stronger. One can find Facebook groups and pages, twitter accounts that are all focused on relationships, marriage friendships, couples, and make the best use of highly significant suggestions and positive contributions they have to offer. Using social media in this way can also facilitate connection with other like-minded people as well as lean towards experts' advice, hear success stories on how others overcame their challenges in marriage, and use that as a model in their relationships. According to Rahul Pandita (2011), social media has played an essential part in ensuring that we stay connected with our dear and near ones. In his view, there are various social media websites out there, and all of them compete to provide the best possible features to the users. Couples can also solve their misunderstanding with the use of social media. For example, when a man offends his wife and does not know how to approach her in person, he can make use of phone messenger to send a text of 
apologies to her, and this has a chance of resolving the conflict between them. Iryna (2012), researched marital satisfaction and the use of social network technologies. The study was carried out in Urbana, using seven families, including 21 individual family members who participated in interviews. The data showed that participants perceived the use of social network sites to influence their satisfaction with family leisure and their family satisfaction in a variety of ways. Among the negative influence were concerns related to communication in the family, insufficient time spent with family, and lack of attention during interactions. Participants also reported the positive impact of social network sites to include an opportunity to update relatives and friends on their family life and development of a sense of belonging, this can as well bring about conflict resolution among couples or family members when it's been discussed and advice being rendered.

\section{METHODOLOGY}

Several methods were adopted for this research; this method range from Area of study, sample technique, instruments adopted for data collection, administering the instrument and method adopted for data analysis.

The area of study is Awka South local government area of Anambra state, south-East Nigeria, in West Africa, with a population of 189,049 as of 2006 Nigerian census. It comprises 21 local government areas made up of nine towns, namely; Amambia, Awka, Ezinato, Isiagu, Mbakwu, Nibo, Nise, Okpuno, and Umuawulu (Lawani 2014).

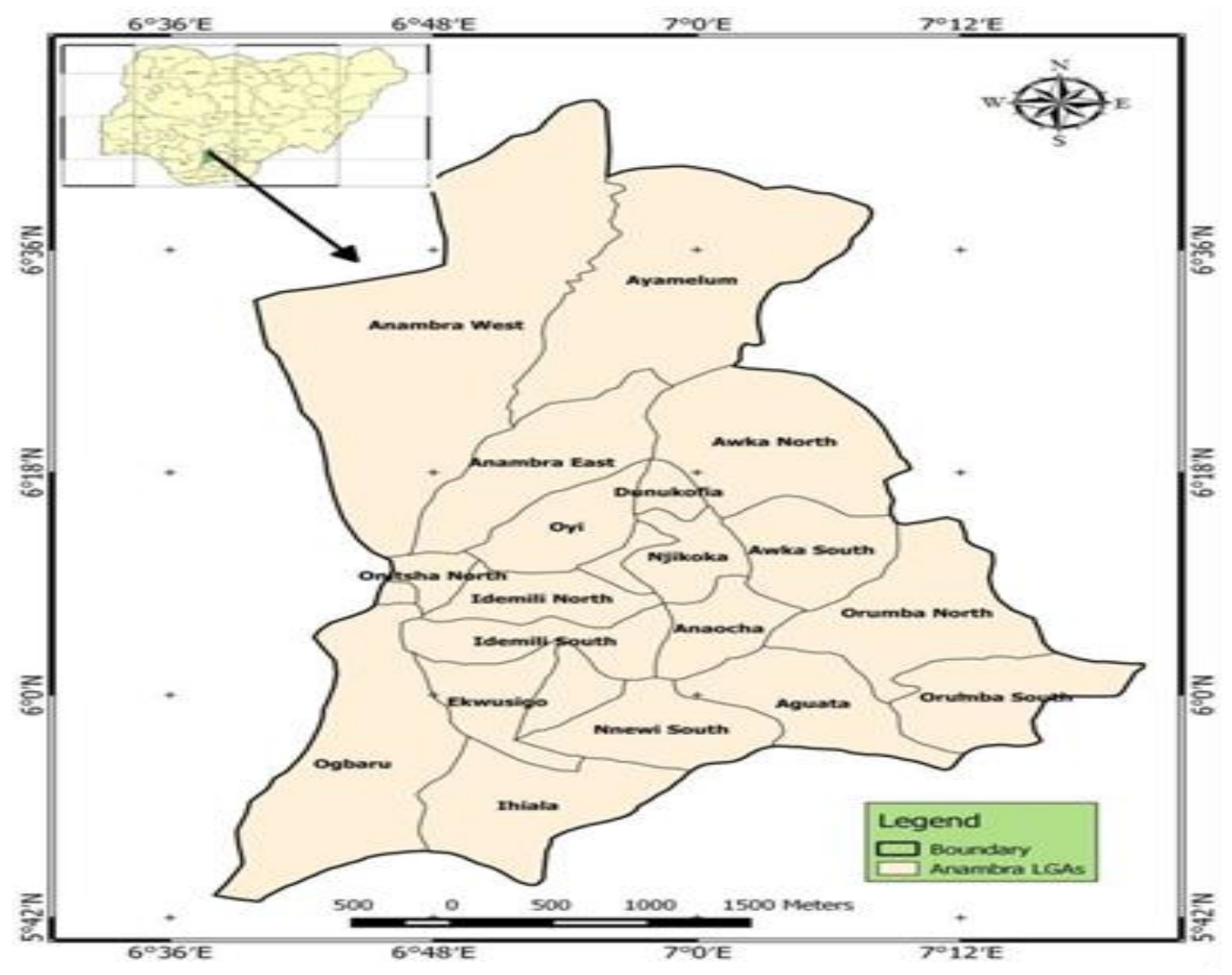


Figure 1: Map of Nigeria to the top upper left showing the location of Anambra state in yellow, and map of Anambra state in indigo showing the location of the study area (Awka South) in red. The map is to scale made evident the coordinate of the region where the research was conducted.

The sample size for this study is 200 respondents who are married couples residing in Umuawulu and Amawbia, both in Awka South, Anambra state. Using a sampling technique that is multi-stage, the major instruments for data collection for the study were questionnaire and which is divided into two sections. Section A contains the personal data of the respondents. These includes questionnaire on their age, sex, marital status, religion, occupation, education qualification, and so on; while the section B contains the substantive issues in the research questions. The in-depth interview consists of open-ended questions aimed at exploring the view points of the respondents on issues that are to be raised and probed when necessary. The in-depth interview was used to collect information from married people. In administering the instruments, the researcher adopted face to face administration of the questionnaire with the aid of two research assistants who were trained by the researcher for a day on the objectives of the study. The researcher personally administered the questionnaire. This is because self-administration of the questionnaire helped the researcher to get firsthand information from the respondents especially on the substantive issues. The research assistants are the note takers and recorder who helped the researcher to clarify some questions which the respondents find difficult to understand. In the in-depth interview, the researcher interviewed the respondents on her own. The collected data were thereafter analyzed using frequency distribution table and simple percentages. The qualitative data was analyzed using the descriptive method of data analysis.

\section{Research Question:}

1. To what extent does social media reduce conflict between couples?

2. Does age of marriage influence the prevalence of marital conflict associated with the use of social media?

3. What are the measures through which conflict associated with the use of social media can be reduced?

This research question is answered by questionnaire and through in-depth interview. The findings are shown in tables 1 and 2 respectively.

Tables 1: Distribution of respondents

\begin{tabular}{|c|c|c|}
\hline Variables & Frequency & Percentage \\
\hline Yes & 100 & 50.8 \\
\hline No & 97 & 49.2 \\
\hline Total & $\mathbf{1 9 7}$ & $\mathbf{1 0 0 . 0}$ \\
\hline
\end{tabular}


Distribution of respondents on whether there are instances in their marital lives where misunderstanding between them and their partners have been resolved with the use of facebook, twitter, watsapp and email

Source: Field survey, 2015

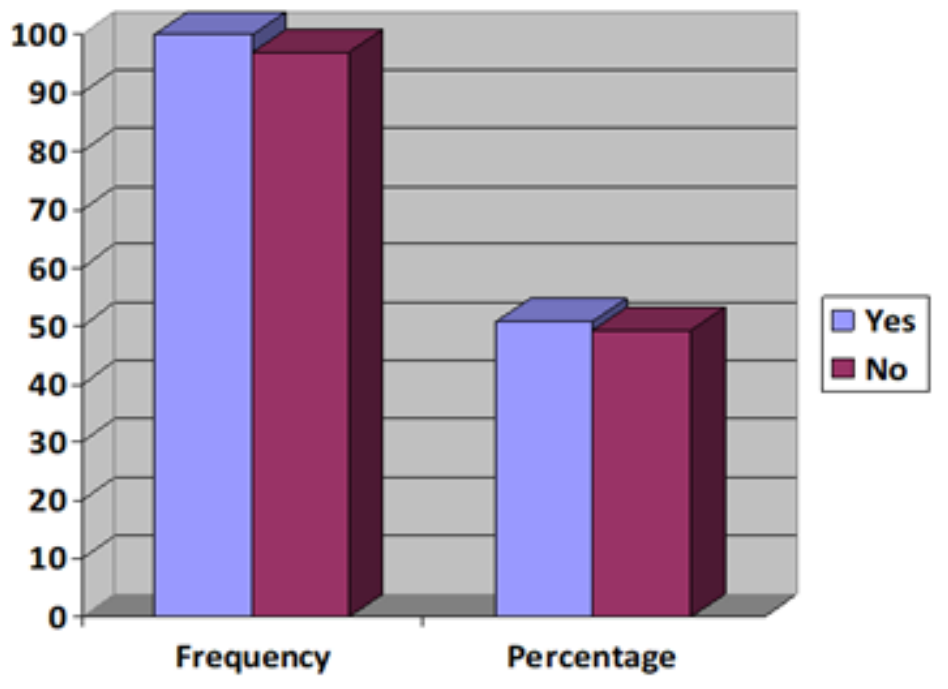

Figure 2: A histogram showing the resulting frequency and percentage distribution of respondents on the question of whether social media helped in the resolution of marital problems

Table 2: Distribution of respondents

\begin{tabular}{|l|l|l|}
\hline Variables & Frequency & Percentage \\
\hline Learning from others experiences online & 33 & 16.8 \\
\hline Posting your marital problem online for friends to comment & 34 & 17.2 \\
\hline Reading online articles on marriage & 47 & 23.9 \\
\hline All of the above & 83 & 42.1 \\
\hline Total & $\mathbf{1 9 7}$ & $\mathbf{1 0 0 . 0}$ \\
\hline
\end{tabular}

This table shows the distribution of respondents on how misunderstanding between them and their partners have been resolved with the use of facebook, twitter and email. Source: Field survey 


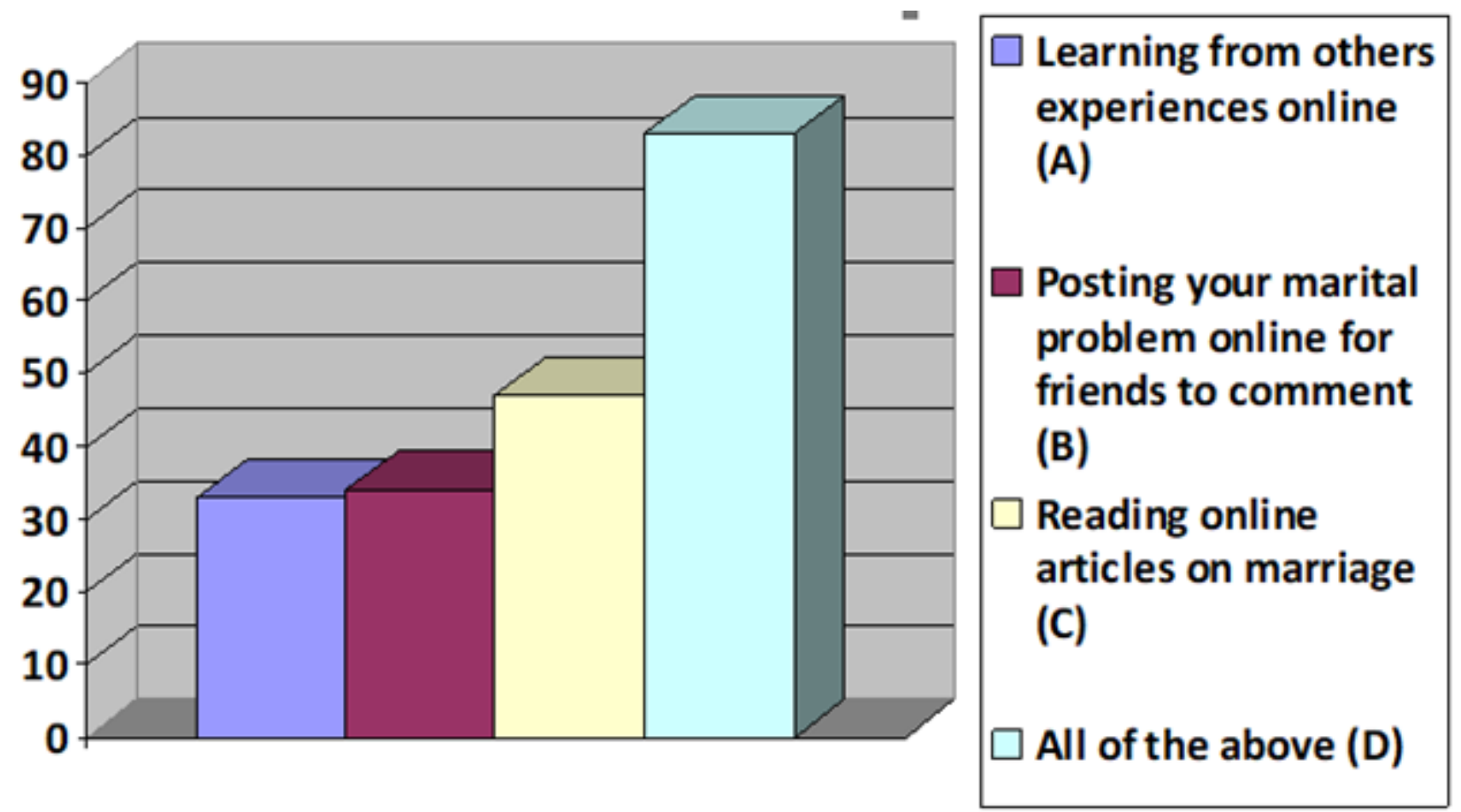

Figure 3: A histogram showing the resulting frequency of variable distribution of respondents on the question of how social media helped in the resolution of marital conflict.

Table 3: Distribution of respondents

\begin{tabular}{|l|l|l|}
\hline Variables & Frequency & Percentage \\
\hline Yes & 177 & 89.8 \\
No & 16 & 8.1 \\
Don`t know & 4 & 2.0 \\
Total & $\mathbf{1 9 7}$ & $\mathbf{1 0 0 . 0}$ \\
\hline
\end{tabular}

This table shows the distribution of respondents on whether they think that age of marriage affects the use of social media by couples.

Source: Field survey 
Table 4: Distribution of respondents

\begin{tabular}{|l|l|l|}
\hline Variables & Frequency & Percentage \\
\hline $\begin{array}{l}\text { Couples who have experienced few years of marriage face } \\
\text { more media related conflict than those who have experienced }\end{array}$ & 143 & 72.6 \\
many years of marriage & \\
$\begin{array}{l}\text { Couples who have experienced many years of marriage face } \\
\text { more media related conflict than those who have experience } \\
\text { few years of marriage }\end{array}$ & 16.2 \\
$\begin{array}{l}\text { Age of marriage does not affect the use of social media } \\
\text { Total }\end{array}$ & 22 & 11.2 \\
\hline
\end{tabular}

This table shows the Distribution of respondents on their views about married couples Source: Field survey

Table 5: Distribution of respondents

\begin{tabular}{|l|l|l|}
\hline Variables & Frequency & Percentage \\
\hline Avoiding the use of passwords on mobile phones & 8 & 4.1 \\
Sharing pleasant moments together & 12 & 6.1 \\
Learning from conflict situations & 32 & 16.2 \\
Couples should only use the media in relating with themselves & 23 & 11.7 \\
or relatives & & \\
All of the above & 118 & 59.9 \\
None of the above & 4 & 2.0 \\
Total & $\mathbf{1 9 7}$ & $\mathbf{1 0 0 . 0}$ \\
\hline
\end{tabular}

This table shows the Distribution of respondents on how to reduce cyber related conflict in marriage. Source: Field survey 


\section{RESUltS}

Table 1 shows that $50.8 \%$ of the respondents confirmed that there are instances in their marital lives where misunderstanding between them and their partners have been resolved with the use of facebook, twitter, watsapp and email, while $49.2 \%$ of them maintained that there are no instances in their marital lives where media platforms resolved misunderstanding in their marital life. This shows that a majority of the respondents stated good of these media platforms as a means to which most of the family misunderstanding were solved.

Table 2 shows that $16.8 \%$ of the respondents identified learning from others experiences online as how misunderstanding between them and their partners have been resolved with the use of facebook, twitter and email, $17.2 \%$ of them opined posting your marital problem online for friends to comment as how misunderstanding between them and their partners have been resolved with the use of facebook, twitter and email, $23.9 \%$ of the respondents identified reading online articles on marriage as how misunderstanding between them and their partners have been resolved with the use of the aforementioned social media and also $42.1 \%$ of them indicated all of the items above as how misunderstanding between them and their partners have been resolved with the use of the media. This shows that a majority of the respondents indicated all of the items listed above as how misunderstanding between them and their partners have been resolved with the use of facebook, twitter and email. This is supported by the qualitative data. An IDI respondent that was interviewed stated:

The truth is that whatever has an advantage also has disadvantage. With good understanding, there is a particular way the media can be used to solve marital problem. For example, charting up friends to relate your problems to them and their ability to contribute by giving you one piece of advice or the other on how best to solve your problem is one of the advantages of the social media. However, let me use this medium to assert that not all the pieces of advice one get from the social media platforms are relevant. Hence, the individual has to choose the best option available to him/her at the end of the day. (IDI, female, 45 years, trader, Awka Urban)

Another IDI respondent noted that:

I think couples should learn to make good use of the media to their own advantage. This means that couples should use the media wisely so as not to misplace priorities. Women should ensure that they are through with their domestic chores before using the social media to avoid disagreement with their husbands. The husbands should learn from peoples` experiences online and read articles on marriage in order to understand how best to tolerate their wives in order to avoid unnecessary conflict associated with the use of the media. (IDI, male, media consultant, Awka Urban).

Table 3 shows that $89.8 \%$ of the respondents believed that age of marriage affects the use of social media by couples, $8.1 \%$ of them did not believe that age of marriage affects the use of social media by couples, while $2.0 \%$ of the respondents maintained that they do not know whether they think that age of marriage affects the use of social media by couples. This shows that a majority of the respondents believed that age of marriage affects the use of social media by couples.

Table 4 shows that $72.6 \%$ of the respondents indicated that couples who have experienced few years of marriage face more media related conflict than those who have experienced many years of marriage, $16.2 \%$ argued that couples who have experienced many years of marriage face more media related conflict than those who have experience few years of marriage, while $11.2 \%$ 
contended that age of marriage does not affect the use of social media. This shows that a majority of the respondents indicated that couples who have experienced few years of marriage face more media related conflict than those who have experienced many years of marriage. This is in line with IDI data. An IDI respondent that was interviewed stated:

Yes, I think that years in marriage influence the rate at which marital conflict associated with the use of media occurs. For instance, those who have stayed less than 6 years in marriage will definitely encounter lots of problems while using the social media because they are still working on understanding each other. However, those who have spent 10 years and above in marriage, already know themselves better and will keep away from whatever will bring problem to their marriage. These older couples already know how to manage the media and their homes better. For example, the wife already has grown children that will assist in domestic activities. As a result, marital conflict associated with the use of the media is reduced to the lowest level. (IDI, male, 48 years, priest, Awka South)

Another IDI respondent stated:

Yes, couples who have few years of marriage experience are likely to have more media related conflict than those who have experienced many years of marriage. Again, the kind of job that couples engage in can easily fuel marital conflict. For instance, a woman married to a web designer/blogger is likely to feel uncomfortable in the relationship because her husband may not give her the needed attention that she expects of him. On the other hand, a married woman may have admirer who may want to always chat with her via the social media platforms. Though she may not accept the idea but the moment the husband senses or sees such chat on her phone or laptop that might be the beginning of marital conflict that may degenerate into divorce if care is not taken. (IDI, male, 48 years, priest, Awka South).

Table 5 shows that $4.1 \%$ of the respondents suggested avoiding the use of passwords on mobile phones as a way to reduce cyber related conflict, $6.1 \%$ of them opined sharing pleasant moments together as how to reduce cyber related conflict in marriage, $16.2 \%$ of the respondents indicated learning from conflict situations as how to reduce cyber related conflict in marriage, $11.7 \%$ of them identified that couples should only use the media in relating with themselves or relatives, $59.9 \%$ of the respondents posited all of the items mentioned above, while $2.0 \%$ of them said none of the above. This shows that a majority of the respondents noted that all the items mentioned above are ways to reduce cyber related conflict in marriage. This is supported by the qualitative data. An IDI respondent that was interviewed stated:

I think that in order to reduce cyber related conflict in marriages in Awka South communities, there should be a level of trust between husband and wife. When there is trust, couples can even exchange passwords with full assurance that the other partner will not betray the trust they both share together. In any case, communication is very important in every marriage. Hence, for marriage to survive the threat that comes from the media and the economic realities of our country, couples should ensure regular spousal communication and should endeavor to resolve all cyber related differences before the next day. (IDI, male, 42 years, media consultant, Awka South)

Another IDI respondent posited that:

It creates mistrust and neglect in the heart of a woman when her husband who is an entrepreneur gets in touch with his clients through the social media frequently especially when he is at home. 
This situation may distract the man from giving his wife and children full attention whenever he is at home. This can lead to doubt in his wife as to whether he is only concern with his business or that he has begun cheating. Hence, to reduce this conflict likely situation from families' couples should totally avoid the use of passwords on their mobile phones whenever they are together as this will a long way to clear lots of doubt in their peaceful relationships. (IDI, male, 48 years, priest, Awak South)

The study however, revealed that there are instances in couples' marital lives where misunderstanding between them and their partners have been resolved with the use of Facebook, twitter, WhatsApp and email. The study discovered that the major instance through which such misunderstanding was resolved is through reading online articles on marriage. Others are learning from others experiences online and posting of marital problems online for friends to comment. This is in agreement with the findings by Dene and Amy (2010) who opined that the use of social media sites like Facebook, twitter, WhatsApp and 2go can pose certain threat to marriages especially those going through difficult times. Despite those hitches, depending on how it is being used, social media can actually make marriage stronger. One can find Facebook groups and pages, twitter accounts that are all focused on relationship, marriages, couples`and make good use of them. Using social media in this way can also help to connect people with other like-minded people as well as tap expert's advice, hear success story on how others overcame their challenges in marriage

\section{CONCLuSion}

Social media is a phenomenon that has transformed the interaction and communications of individuals throughout the world. It has been evolving since the dawn of human interaction, thereby impacting marriages and businesses. Although marital conflict can arise as a result of improper use of the social media, proper and adequate use of it can make significant positive impact in the life of married couple. It was observed in the study that social media has gone a long way in preventing marital conflict; this observation is the firm ground for which recommendation on the implementation of media programs to educate couples on how best to use social media are made. This recommendation if implemented will help combat conflicts, improve communication and most importantly enrich the health of the family. 


\section{References}

Asian Journal of Management Research, volume 5, issue 3, 2015: Retrieved from http://www.researchgate.net/publication/271446578 work life balance of women employees in information technology.

Askari, M., Noah, S. B. M., Hassan, S. A. B., \& Baba, M. B. (2012). Comparison the effects of communication and conflict resolution skills training on marital satisfaction. International Journal of Psychological Studies, 4(1), 182-195. doi:10.5539/ijps.v4n1p182

Backyard Sociology fall (2011); marriage and conflict theory: Retrieved from http://backyardsociologyfall2011.blogspot.com/

Bharati V. (2015), life balance of women employees in the information technology industry. Retrieved from http://www.researchgate.net/publication/271446578 work-life-balance-of-women-employees-in-theinformation-technology-industry.

Birditt, K. S., Brown, E., Orbuch, T. L., \& McIlvane, J. M. (2010). Marital conflict behaviors and implications for divorce over 16 years. Journal of Marriage and Family, 72(5), 1188-1204. doi:10.1111/j.1741-3737.2010.00758.x

Cohen S, Willis TA. Stress, social support, and the buffering hypothesis. Psychological Bulletin. 1985;95:310-357. doi: 10.1037/0033-2909.98.2.310.

Cox MJ, Paley B. Families as systems. Annual Review of Psychology. 1997;48:243-267. doi: 10.1146/annurev.psych.48.1.243.

D’Vera Cohn (2010). Women, men and new economics of marriage: Retrieved from http://www.pewsocialtrends.org/2010/01/19/women-men-and-the-new-economics-ofmarriage/\#content

Dong, M. C., \& Li, S. Y. (2007). Conflict resolution in Chinese family purchase decisions: The impact of changing female roles and marriage duration. International Journal of Conflict Management, 18(4), 308-324. doi:10.1108/10444060710833441

Dush, C. M. K., \& Taylor, M. G. (2012). Trajectories of marital conflict across the life course: Predictors and interactions with marital happiness trajectories. Journal of Family Issues, 33(3), 341-368. doi:10.1177/0192513X11409684.

Gottman, J. M. (1994). Why marriages succeed or fail. New York, NY: Simon \& Schuster.

Hostinar CE, Sullivan RM, Gunnar MR. Psychobiological mechanisms underlying the social buffering of the hypothalamic-pituitary adrenocortical axis: A review of animal and human studies across development. Psychological Bulletin. 2014;140:256-282. doi: 10.1037/a0032671.

Kaitohutohu Kaupapa Rawa (2004); theories of the family and policy: Retrieved from http://www.treasury.govt.nz/publications/research-policy/wp/2004/04-02/11

Kira S. Birditt, Edna; Marital conflict behaviors and implications for divorce over 16 years: Retrieved from http://www.ncbi.nlm.nih.gov./pmc/articles/pmc3777640/

Kurdek, L. A. (1994b). Conflict resolution styles in gay, lesbian, heterosexual nonparent, and heterosexual parent couples. Journal of Marriage and Family, 56(3), 705-722. doi:10.2307/352880

Lawani (2014). Sources and consequences of marital conflicts among working class couples of Anambra state. 
Leggett, D. G., Roberts-Pittman, B., Byczek, S., \& Morse, D. T. (2012). Cooperation, conflict, and marital satisfaction: Bridging theory, research, and practice. The Journal of Individual Psychology, 68(2), 182199.

Norgren, M. B. P., Souza, R. M., Kaslow, F., Hammerschmidt, H., \& Sharlin, S. A. (2004). Satisfação conjugal em casamentos de longa duração: Uma construção possível [Marital satisfaction in long lasting marriages: A feasible construction]. Estudos de Psicologia (Campinas), 9(3), 575-584. doi:10.1590/S1413-294X2004000300020

Rahal Pandita (2011), how does social media affect relationship: Retrieved from http://www.buzzle.com/articles/how-does-social-media-affect-relationships.html.

Ridley, C. A., Wilhelm, M. S., \& Surra, C. A. (2001). Married couples' conflict responses and marital quality. Journal of Social and Personal Relationships, 18(4), 517-534. doi:10.1177/0265407501184005

Robles TF, Slatcher RB, Trombello JM, McGuinn MM. Marital quality and health: A meta-analytic review. Psychological Bulletin. 2014;140:140-187. doi: 10.1037/a0031859.

Rogge, R., and Bradbury, T. (1999). Till violence does us part: the differing roles of communication and aggression in prediction adverse marital outcomes Journal of consulting and clinical psychology, 67(3),340-351.

Ryan (2012), marital satisfaction and the use of social network technologies

S. Grey, demand media (ND), conflict theory and divorce: Retrieved from http://everydaylife.globalpost.com/conflict-theory-divorce-19782.htm/\#main.

Scheeren, P., Vieira, R. V. A., Goulart, V. R., \& Wagner, A. (2014). Marital quality and attachment: The mediator role of conflict resolution styles. Paidéia (Ribeirão Preto), 24(58), 177-186. doi:10.1590/1982-43272458201405

Sener Gulum (2012), digital love: romantic relationship in social networking sites. Available at, gulum sener University, faculty of communication media and communication systems.

Timmons, A. C., Arbel, R., \& Margolin, G. (2017). Daily patterns of stress and conflict in couples: Associations with marital aggression and family-of-origin aggression. Journal of Family Psychology, 31(1), 93-104. https://doi.org/10.1037/fam0000227

Uchino BN. Social support and health: A review of physiological processes potentially underlying links to disease outcomes. Journal of Behavioral Medicine. 2006;29:377-387. doi: 10.1007/s10865-006-9056-5. 